\title{
Twin pregnancy, the study of maternal and perinatal outcome: what being a twin is like?
}

\author{
Smitha K., Jasiya Afreen M. H.*
}

Department of Obstetrics and Gynecology, KIMS, (RGUHS-Affiliated) Bengaluru, Karnataka, India

Received: 09 August 2019

Accepted: 30 September 2019

\section{*Correspondence:}

Dr. Jasiya Afreen MH,

E-mail: drjasi14@gmail.com

Copyright: (C) the author(s), publisher and licensee Medip Academy. This is an open-access article distributed under the terms of the Creative Commons Attribution Non-Commercial License, which permits unrestricted non-commercial use, distribution, and reproduction in any medium, provided the original work is properly cited.

\begin{abstract}
Background: Twin pregnancy is considered as a high-risk pregnancy due to associated high maternal and perinatal morbidity mortality in comparison with singleton pregnancy. The objectives of this study were to study the maternal and perinatal complications in twin pregnancies. To find out various factors that contribute to adverse perinatal outcome.

Methods: This retrospective study was conducted at Kempegowda Institute of Medical Sciences Hospital, Bengaluru. 92 women with twin pregnancies admitted in KIMS Hospital from September 2014 to September 2018, both booked and referred patients were studied. Individual patient parameters like age, parity, gestational age, mode of delivery, maternal complications were tabulated. Neonatal morbidity and mortality were noted, data thus obtained was analysed and results studied.

Results: In the study the incidence of twin pregnancies was more in second gravida (53\%). $72 \%$ of the patients were admitted between 28-36 weeks of gestation with preterm labour (23\%) as the main cause for admission. Anaemia (8.69\%), hypertensive disorders of pregnancies (17.39\%), PPROM (21\%), single foetal demise (5\%) and IUGR (5.4\%) were the antenatal complications observed. Out of the 92 patients, $29(35.4 \%)$ patients delivered by vaginal route whereas $53(64.6 \%)$ had to undergo C-section. DCDA twin constituted $66 \%$ of twins in the study and mal presentation was the commonest indication for caesarean section (50\%). Among the 164 babies out of 92 twin pregnancies 8 babies were still born and 12 babies died by the end of one week due to complications related to prematurity like hyaline membrane disease, IVH.

Conclusions: Early detection of twin pregnancies and proper antenatal care reduces both maternal and perinatal complication thereby improving maternal and perinatal outcome.
\end{abstract}

Keywords: Assisted reproductive technology, Intrauterine growth retardation, Maternal outcome, Neonatal mortality, Preterm labor, Twins

\section{INTRODUCTION}

The number of multiple pregnancies is on rise due to use of ART. Worldwide incidence of multiple pregnancies varies considerably. Multifetal pregnancies may result from two or more fertilization events, from a single fertilization followed by an erroneous splitting of the zygote or from a combination of both. Multiple pregnancies are associated with increased risk for both the mother and child, and this risk increases with the number of offspring. For example, $60 \%$ of twins, $90 \%$ of triplets and virtually all of quadruplets are born preterm. ${ }^{1}$

Twin fetuses usually result from fertilization of two separate ova - Dizygotic or fraternal twins. Less often, twins arise from a single fertilized ovum that divides monozygotic or identical twins. ${ }^{2}$ 
Dizygotic twinning is much more common than monozygous splitting of a single oocyte. The frequency of monozygotic twin births is relatively common worldwide, approximately one set per 250 births. This incidence is generally independent of race, hereditary, age and parity. By contrast the incidence of dizygotic twinning is influenced by race, heredity, maternal age, parity, and especially, fertility treatment. ${ }^{3}$

Twin pregnancy is considered as a high-risk pregnancy. ${ }^{4}$ Twin pregnancy is known to have more obstetrical and neonatal complications as compared to singleton pregnancy. The obstetric complications of multifetal pregnancy include hyperemesis gravidarum, gestational diabetes, polyhydramnios, preterm labour, preterm premature rupture of membranes, anaemia, pregnancyinduced hypertension, postpartum haemorrhage, etc. ${ }^{5-7}$ The risk of maternal mortality is approximately 2.5 times higher in twin than in singleton pregnancies.

Perinatal mortality and morbidity in twin pregnancy is five-seven times higher compared to singleton pregnancy. ${ }^{8}$ Prematurity, low birth weight (LBW), birth asphyxia, birth trauma, intrauterine foetal death and congenital malformations are the important factors to explain the reasons of high perinatal mortality. For twin pregnancies, in most countries the average caesarean section (LSCS) rate is about $50 \% .^{9,10}$

The study of twin or multiple births is important because of the elevated health risks for both mothers and babies and accompanying greater health care cost. The study is undertaken as early and accurate prenatal diagnosis, detection and management of maternal and fetal complications are the major priorities in the management of twin pregnancies. Planning the time and mode of delivery in complicated twin pregnancies and early detection of monochorionic placentation and managing its consequences are crucial steps leading to a higher probability of successful outcome.

The objectives of this study were to analyse the maternal and fetal outcome in twin gestations. To find out various factors that contribute to adverse perinatal outcome.

\section{METHODS}

It is a retrospective study conducted in the department of Obstetrics and Gynaecology, Kempegowda Institute of Medical Sciences Hospital and Research Center, Bengaluru. Labour room statistics were taken and studied from September 2014 to September 2018. 92 women with twin pregnancies, admitted (both booked or referral cases) were studied. Women $>18$ years of age with twin pregnancies and gestational age $>10$ weeks were included in the study. Women with grand multiparity and twin pregnancies with $<10$ weeks of gestation were excluded from the study. Individual patient parameters like parity, gestational age, mode of delivery, complications were tabulated. Neonatal morbidity and mortality were noted.
The results thus obtained, were analysed and recorded in percentage and frequencies.

\section{Statistical analysis}

Data was entered into Microsoft excel data sheet and was analysed using SPSS 22 version software. Categorical data was represented in the form of Frequencies and proportions. Chi-square test or Fischer's exact test (for $2 \times 2$ tables only) was used as test of significance for qualitative data.

Continuous data was represented as mean and standard deviation. Independent t-test was used as test of significance to identify the mean difference between two quantitative variables. Paired t-test is the test of significance for paired data for quantitative data. ANOVA test was used as test of significance to identify the mean difference between more than two quantitative variables.

Graphical representation of data: MS Excel and MS word were used to obtain various types of graphs such as bar diagram, Pie diagram. p-value (Probability that the result is true) of $<0.05$ was considered as statistically significant after assuming all the rules of statistical tests. MS Excel, SPSS version 22 (IBM SPSS Statistics, Somers NY, USA) was used to analyze data.

\section{RESULTS}

From September 2014 to September 2018 authors had 92 patients with twin pregnancies. The incidence of twin pregnancy in the study is $1.64 \%$.

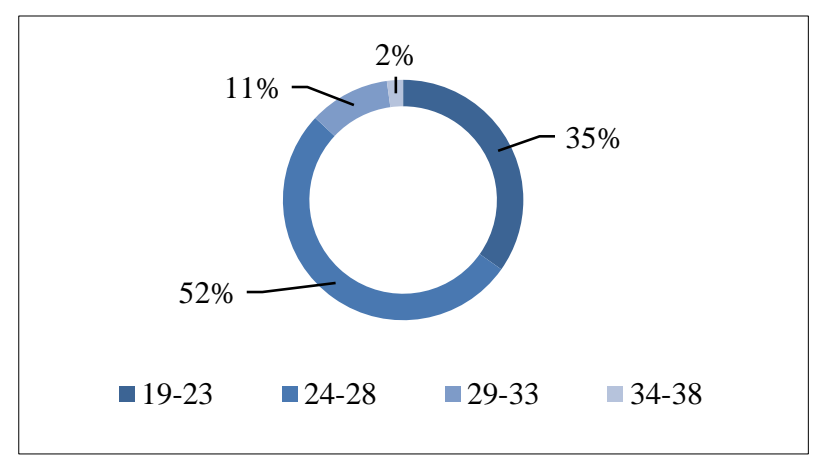

Figure 1: Age.

$52 \%$ of patients from our study belong to age group $19-$ 23 years, followed by $35 \%$ of them belonging to $24-28$ years age group signifying high incidence of multiple pregnancies in extremes of reproductive age group (Figure 1).

Our hospital being a referral hospital, our study had $60 \%$ of cases being un-booked or referred to our hospital for further management (Figure 2). 


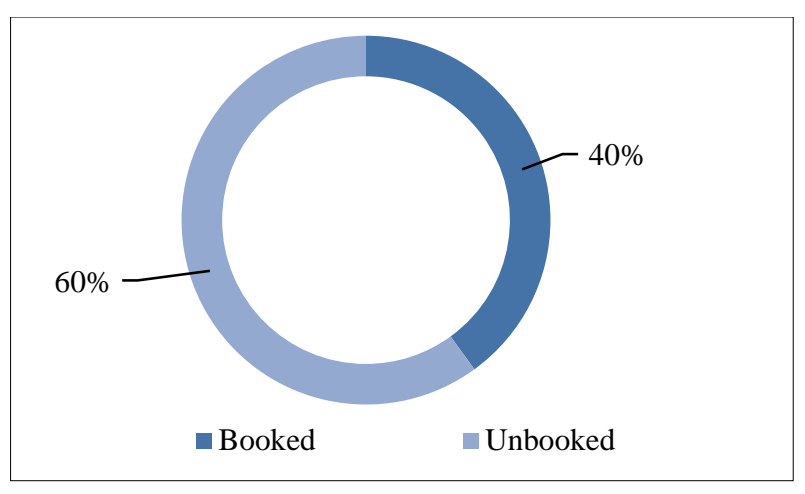

Figure 2: Booking status.

In our study, maximum number of patients were second gravida $(53 \%), 36 \%$ were primigravida and $11 \%$ were third gravida (Figure 3).

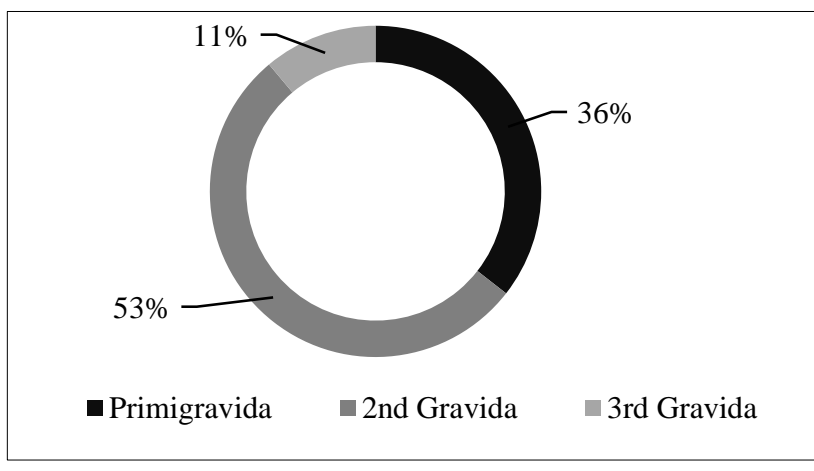

Figure 3: Gravida status.

In this study, 15 patients had twin pregnancies as a result of ARTs, 9 patients with ovulation induction drugs $(9.80 \%), 5$ cases with IUI $(5.43 \%)$ and 1 patient with IVF (Table 1).

Table 1: Assisted reproductive technique.

\begin{tabular}{|lll|}
\hline ARTs & Number $(\mathbf{n = 9 2})$ & Percent \\
\hline Ovulation Induction & 09 & 9.80 \\
\hline IUI & 05 & 5.43 \\
\hline IVF & 1 & 1.08 \\
\hline
\end{tabular}

The most common type of twins in the study was DCDA accounting to 71.73 percent, followed by MCDA twins and a very few MCMA twins. There were no cases of conjoined twins (Table 2).

Table 2: Type of twins.

\begin{tabular}{|lll|}
\hline Type & Number $(n=92)$ & Percent \\
\hline MCMA & 6 & 6.52 \\
\hline MCDA & 20 & 21.70 \\
\hline DCDA & 66 & 71.73 \\
\hline
\end{tabular}

In this study, we had $56 \%$ of patients belonging to $32-36$ weeks of gestational age with preterm labour being the commonest indication for admission. We had 8 patients with $<24$ weeks of gestation with inevitable abortion, and 5 patients with 25-29 weeks of gestation admitted for PPROM (Table 3).

Table 3: Gestational age.

\begin{tabular}{|lll|}
\hline Gestational age & Number $(\mathbf{n}=92)$ & Percent \\
\hline$<24$ weeks & 08 & 8.70 \\
\hline 25 weeks $-28^{+6}$ weeks & 05 & 5.43 \\
\hline 29 weeks $-31^{+6}$ weeks & 13 & 14.10 \\
\hline 32 weeks -36 weeks & 52 & 56.50 \\
\hline$>36$ weeks & 11 & 12.00 \\
\hline
\end{tabular}

Our hospital being a referral centre, most cases were referred in complicated state, hence LSCS rate was $64.60 \%$. In that 41 patients underwent emergency LSCS and 12 had elective LSCS. Most common indication being mal-presentation (Table 4).

Table 4: Mode of delivery.

\begin{tabular}{|ll|l|}
\hline Delivery & Number $(\mathbf{n}=\mathbf{8 2})$ & Percent \\
\hline Vaginal & 29 & 35.40 \\
\hline LSCS & 53 & 64.60 \\
\hline
\end{tabular}

The most common maternal complication and the commonest cause for admission in the study was preterm labour. 22 patients had preterm labour the study, 20 patients had PPROM. 10 patients had miscarriage in our study and majority were inevitable (Table 5).

\section{Table 5: Maternal complications.}

\begin{tabular}{|lll|}
\hline Maternal complications & $\begin{array}{l}\text { Number } \\
(\mathrm{n=92})\end{array}$ & Percent \\
\hline Pretem labor & 22 & 23.91 \\
\hline PPROM & 20 & 21.73 \\
\hline Hypertension & 16 & 17.39 \\
\hline GDM & 03 & 3.26 \\
\hline Anaemia & 8 & 8.69 \\
\hline IUGR & 5 & 5.43 \\
\hline Abortions & 10 & 10.86 \\
\hline Hydramnios & 2 & 2.17 \\
\hline APH & 1 & 1.08 \\
\hline TTTS & 2 & 2.17 \\
\hline Single fetal demise & 5 & 5.43 \\
\hline
\end{tabular}

In this study, authors had 27 cases of malpresentation, and 11 cases of previous LSCS in labor not willing for TOLAC (Table 6).

In this study, among 164 babies 105 babies had low birth weight (birth weight $1.6-2.5 \mathrm{~kg}$ ) and only 3 babies were above $3 \mathrm{~kg}$.

Out of 164 babies, 8 were stillborn, 156 babies were alive (Table 7). 
Table 6: Indication for LSCS.

\begin{tabular}{|lcl|}
\hline Indication for LSCS & Number $(\mathbf{n = 9 2})$ & Percent \\
\hline Malpresentation & 27 & 50.95 \\
\hline Prev LSCS in labor & 11 & 20.75 \\
\hline Fetal distress & 05 & 9.44 \\
\hline Social reason & 04 & 7.55 \\
\hline Non progression of labor & 02 & 3.77 \\
\hline Severe PE & 04 & 7.54 \\
\hline
\end{tabular}

Table 7: birth weight.

\begin{tabular}{|ll|}
\hline Groups & Number of babies $(\mathrm{n}=164)$ \\
\hline$<1.5 \mathrm{~kg}$ & $43(26.22 \%)$ \\
\hline $1.5-2.5 \mathrm{~kg}$ & $105(64.02 \%)$ \\
\hline $2.5-3 \mathrm{~kg}$ & $13(7.96 \%)$ \\
\hline$>3 \mathrm{~kg}$ & $3(1.82 \%)$ \\
\hline
\end{tabular}

Table 8: Cause of neonatal death.

\begin{tabular}{|ll|}
\hline Cause & Number of deaths \\
\hline RDS & $9(47.4 \%)$ \\
\hline IVH & $6(31.57 \%)$ \\
\hline Septicaemia & $4(21.5 \%)$ \\
\hline
\end{tabular}

Out of 164 total birth, 9 babies died due to RDS, and 6 of them died due to IVH, and 4 death due to septicaemia (Table 8).

Table 9: NICU admission.

\begin{tabular}{|ll|}
\hline Admission & $(\mathbf{n}=\mathbf{1 5 6})$ \\
\hline Not required & 21 \\
\hline Required & 135 \\
\hline
\end{tabular}

Out of 156 live babies 135 required NICU admission, LBW being the most common indication for NICU admission (Table 9).

Table 10: APGAR score.

\begin{tabular}{|ll|}
\hline In 1 minute & $(\mathrm{n}=\mathbf{1 5 6})$ \\
\hline$<8$ & $72(46.15 \%)$ \\
\hline$>8$ & $84(53.85 \%)$ \\
\hline
\end{tabular}

APGAR was $<8$ at 1 min of birth in 72 babies and $>8$ at 1 min in 84 babies in our observation (Table 10).

\section{DISCUSSION}

Incidence of twins in our study- (1.64\%) which is much higher than the incidence of twins in India which is around $0.9 \%-1 \%$.

Our institution being a tertiary referral centre, had referrals from many of the PHC's and private hospitals for better neonatal care in anticipation of complications in neonates.
Our results with respect to the incidence of twins were consistent with study done by Bangal et al, in which the incidence of twins was $1.49 \% .^{15}$

In this study, maximum patients were second gravida $53 \%, 36 \%$ were primigravida and $11 \%$ were third gravida. The results were consistent with Singh et al and Chowdhury et al, studies on twins in which the incidence of twins in multigravida were $70.7 \%$ and $64.2 \%$ respectively. ${ }^{16}$

The caesarean section rate in this study was $53(64.6 \%)$. This was consistent with MB Shetty et al, 134 (68.02\%) had to undergo C-section. ${ }^{17}$

The increase in the use of cesarean section to deliver twin pregnancies may be due to increased incidence of other obstetric indications for cesarean deliveries such as hypertensive disorders, malpresentation, cord prolapse, and premature rupture of membranes as observed in this study.

Mode of delivery was not associated with any difference in outcome.

In this study $58(70.7 \%)$ were dichorionic diamniotic pregnancy, comparable to a study done in Kerala by Radhakrishnan $\mathrm{R}$ et al, who found that 62 percent of the cases were dichorionic diamniotic pregnancy, $37 \%$ mono-chorionic diamniotic pregnancy. ${ }^{18}$

In this study, majority (43) of twins was found in age group of 24-28 years, consistent with studies done by Singh et al (21-26 years) and Bangal et al (20-30 years).

In complications, our study had 21\% PROM case $23 \%$ preterm labor, $17 \%$ hypertension cases $8.69 \%$ anaemia cases, and $1.08 \%$ APH cases all were comparable to study done by Bangal et al and Chowdhary et al.

In the present study, prematurity $-84 \%$, low birth weight - $90 \%$, IUGR - $5.43 \%$.

The results were consistent with other studies Bangal et al, $21 \%$ cases had neonatal morbidity Singh et al, $74.67 \%$ twins were premature, $9.5 \%$ had IUGR, $26.76 \%$ were admitted in NICU.

In the present study, perinatal mortality was found in $16.4 \%$ cases. Bangal et al, Sheeela et al, Pandey et al, and Singh et al, found it to be $17.5 \%, 12.09 \%, 9.64 \%$ and $10.3 \%$ respectively. ${ }^{19,20}$

\section{CONCLUSION}

Twin pregnancy is a high-risk pregnancy with high maternal and perinatal morbidity and mortality. LBW, preterm labour, IUGR which are the important factors for the neonatal deaths. Perinatal morbidity and mortality can be reduced considerably if authors can achieve birth 
weight of more than $1.5 \mathrm{~kg}$ in twins. Determination of chorionicity at the earliest and with proper antenatal care is essential to decrease the complications especially in monochorionic twins. Judicious use of ART can reduce the incidence of multiple pregnancy and thereby its complications.

Funding: No funding sources Conflict of interest: None declared

Ethical approval: The study was approved by the Institutional Ethics Committee

\section{REFERENCES}

1. Martin JA, Hamilton BE, Ventura SJ. Births. Final data for 2010. Natl Vital Stat Rep. 2012;61(1):1.

2. Cunningham FG, Leveno KG, Bloom SL, Sponge CY, Dashe JS, Hoffman BL, et al. Multifetal pregnancy. In: Williams Obstetrics $\left(24^{\text {th }}\right.$ ed). New York; 2014:891-924.

3. Aston K, Peterson C, Carrell D. Monozygotic twinning associated with assisted reproductive technologies: a review. Reprod. 2008;136(4):377.

4. Vanaja G, Devi PU, Devi DH, Prasad U, Kumari PD, Madhuri Y. Maternal and perinatal outcome in twin gestation in a referral hospital at Visakhapatnam. 2018.

5. Young BC, Wylie BJ. Effects of twin gestation on maternal morbidity. Semin Perinatol. 2012;36:162-8.

6. Tilahun T, Araya F, Tura G. Incidence and risk factors of twin pregnancy at Jimma University Specialized Hospital, Southwest Ethiopia. Epidemiol. 2015;5:188.

7. National Institute for Health and Clinical Excellence. Multiple pregnancy. The management of twin and triplet pregnancies in the antenatal period. NICE clinical Guideline. 2011. Available at: http://guidance.nice.org.uk/cg129.

8. Dutta DC. Textbook of obstetrics including perinatology and contraception. $6^{\text {th }}$ ed. Calcutta: New Central Book Agency (P) Ltd; 2013.

9. Vendittelli $\mathrm{F}$, Rivière $\mathrm{O}$, Crenn-Hébert CA, Riethmuller D, Schaal JP, Dreyfus M. Is a planned cesarean necessary in twin pregnancies ? Acta Obstetricia Gynecol Scandinavica. 2011;90(10):1147-56.
10. Adler-Levy Y, Lunenfeld E, Levy A. Obstetric outcome of twin pregnancies conceived by in vitro fertilization and ovulation induction compared with those conceived spontaneously. Eur J Obstet Gynecol Reprod Biol. 2007;133:173-8.

11. Rosner B, Fundamentals of Biostatistics, $5^{\text {th }}$ Edition, Duxbury. 2000:80-240.

12. Riffenburg RH. Statistics in Medicine, second edition, Academic press. 2005:85-125.

13. Rao PSS, Richard J. An Introduction to Biostatistics, A manual for students in health sciences, New Delhi: Prentice hall of India. 4th edition; 2006:86-160.

14. Suresh KP, Chandrasekhar S. Sample size estimation and power analysis for clinical research studies. J Human Reprod Sci. 2014;5(1):7-13.

15. Bangal VB, Patel SM, Khairnar DN. Study of maternal and foetal outcome in twin gestation at tertiary care teaching hospital. IJBAR. 2012;3(10):758.

16. Chowdhury S, Hussain MA. Maternal complications in twin pregnancies. MMJ. 2011;20(1):83-7.

17. Shetty MB, Shivananjaiah C, Swarup A. A retrospective study: twin gestation at tertiary care, maternal and fetal outcome. Int J Reprod Contracept Obstet Gynecol. 2016;5:217-9.

18. Radhakrishnan R, Radhakrishnan R. Perinatal outcome of twin pregnancy and influence of chorionicity on it. Int $\mathbf{J}$ Prev Ther Med. 2014;2(1):10-4.

19. Sheela SR, Patila A. A study of maternal and foetal outcome in multifoetal gestation at a rural based teaching hospital-a retrospective analysis. Int J Biol Med Res. 2014;5(2):3994-7.

20. Pandey MR, Kshetri BJ, Dhakal D. Maternal and perinatal outcome in multifetal pregnancy: a study at a teaching hospital. Am J Public Health Res. 2015;3(5A):135-8.

Cite this article as: Smitha K, Afreen JMH. Twin pregnancy, the study of maternal and perinatal outcome: what being a twin is like?. Int J Reprod Contracept Obstet Gynecol 2019;8:4457-61. 